\title{
Role of the tumor immune microenvironment in tumor immunotherapy (Review)
}

\author{
CHANGSHENG ZHOU ${ }^{1-5}$, QIANQIAN LIU ${ }^{1,3}$, YI XIANG ${ }^{2}$, XIN GOU $^{2}$, and WENGANG LI ${ }^{1,3-5}$ \\ ${ }^{1}$ Department of Hepatobiliary Surgery, Xiang'an Hospital of Xiamen University, School of Medicine, Xiamen University, \\ Xiamen, Fujian 361102; ${ }^{2}$ Department of Hepatobiliary Surgery, Guizhou Provincial People's Hospital, Guiyang, \\ Guizhou 550002; ${ }^{3}$ School of Medicine, ${ }^{4}$ Cancer Research Center of Xiamen University and ${ }^{5}$ Retroperitoneal Tumor Research \\ Center of Oncology Chapter of Chinese Medical Association, Xiamen University, Xiamen, Fujian 361102, P.R. China
}

Received October 9, 2021; Accepted December 2, 2021

DOI: $10.3892 / \mathrm{ol} .2021 .13171$

\begin{abstract}
Tumor immunotherapy is considered to be a novel and promising therapy for tumors and it has recently become a hot research topic. The clinical success of tumor immunotherapy has been notable, but it has been less than totally satisfactory because tumor immunotherapy has performed poorly in numerous patients although it has shown appreciable efficacy in some patients. A minority of patients demonstrate durable responses but the majority of patients do not respond to tumor immunotherapy as the tumor immune microenvironment is different in different patients for different tumor types. The success of tumor immunotherapy may be affected by the heterogeneity of the tumor immune microenvironment and its components, as these vary widely during neoplastic progression. The deepening of research and the development of technology have improved our understanding of the complexity and heterogeneity of the tumor immune microenvironment and its components, and their effects on response to tumor immunotherapy. Therefore, investigating the tumor immune microenvironment and its components and elucidating their association with tumor immunotherapy should improve the ability to study, predict and guide immunotherapeutic responsiveness, and uncover new therapeutic targets.
\end{abstract}

Correspondence to: Professor Xin Gou, Department of Hepatobiliary Surgery, Guizhou Provincial People's Hospital, 83 Zhongshandong Road, Guiyang, Guizhou 550002, P.R. China E-mail: gouxingzsy@126.com

Professor Wengang Li, Department of Hepatobiliary Surgery, Xiang'an Hospital of Xiamen University, School of Medicine, Xiamen University, 4221 Xiang'annan Road, Xiamen, Fujian 361102, P.R. China

E-mail:1wg11861@163.com

Key words: tumor immune microenvironment, tumor immunotherapy, immune cells, non-immune cells, immune checkpoint

\section{Contents}

1. Introduction

2. Tumor cells and their function

3. Immune cells and tumor immunotherapy

4. Non-immune cells and tumor immunotherapy

5. Cytokines and tumor immunotherapy

6. Immune checkpoints and tumor immunotherapy

7. Conclusions

\section{Introduction}

Over the past decade, tumor treatment has been revolutionized by moving away from chemotherapy and radiation and toward tumor immunotherapy and targeted therapy. Tumor immunotherapy, which modulates immune responses against tumors, has shown appreciable efficacy in multiple cancer types and is considered to be a novel and promising therapy for tumors. However, the efficacy of tumor immunotherapy has been found to be poor in the majority of patients, despite its notable efficacy in in an appreciable proportion of patients with cancer (1-3). It has been reported that the hyporesponsiveness or unresponsiveness of patients to tumor immunotherapy may be due to the heterogeneity of the tumor immune microenvironment (TIME) $(4,5)$. The TIME and its components may vary widely during neoplastic progression and among different patients, and these variations, as well as the heterogeneity of the TIME and its components, have a profound effect on the outcome of tumor immunotherapy $(4,5)$. As a result, it is crucial to understand the roles of the TIME and its components during neoplastic progression and in different patients in order to improve the efficacy of tumor immunotherapy. With the deepening of research and the development of technology, our understanding of the complexity and heterogeneity of the TIME and its components and their effects on the response of patients to tumor immunotherapy has also improved. Deeper analysis of the complexity and heterogeneity of the TIME and its components is likely to uncover advanced biomarkers that may prove useful in identifying patient populations responsive to current tumor immunotherapy, and will benefit the search for novel targets for therapeutic modulation. The aim of the 
present review was to provide a summary of the current knowledge centered around the TIME, focusing on its components and their association with tumor immunotherapy, in order to improve the ability to study, predict and guide immunotherapeutic responsiveness and uncover novel therapeutic targets.

\section{Tumor cells and their function}

Tumor cells, the dominant cellular components of the TIME, play an important role in the TIME, and they can directly inhibit the function of immune cells via secreting tumor antigens or creating a microenvironment that is not conducive to the metabolism of immune cells, thereby causing inactivation and inhibition of immune cell function (6). The tumor cells can also inhibit the function of immune cells through secreting inhibitory cytokines, capturing chemokines, secreting VEGF, which can suppress dendritic cell (DC) maturation and activate regulatory $\mathrm{T}$ cells (Tregs) directly, and activating immune checkpoints $(6,7)$.

\section{Immune cells and tumor immunotherapy}

Immune cells, also a dominant cellular component of the TIME, serve an important role in the TIME, principally consist of T cells, B cells, monocytes-macrophages, natural killer (NK) cells, DCs and their subsets.

T cells. T cells, the main immune cells in the TIME, induce an antitumor immune response by recognizing antigens on tumor cells. The proportion and subsets of $\mathrm{T}$ cells in the TIME are the major factors affecting tumor progression (8).

Exhaustive $\mathrm{T}$ cells, a special subset of $\mathrm{T}$ cells, are characterized by dysmetabolic disorder, poor self-renewal ability, piecemeal loss of function, as well as sustained high expression of inhibitory immune checkpoints like cytotoxic lymphocyte antigen-4 (CTLA-4), programmed cell death protein-1 (PD-1), T-cell immunoglobulin and mucin-domain containing-3 (TIM-3), lymphocyte activation gene-3 (LAG-3) and T-cell immunoglobulin and ITIM domain (TIGIT), among others $(8,9)$. T-cell exhaustion can be classified into 'pre-exhaustion' and 'terminal exhaustion' stages. 'Pre-exhausted' T cells retaining their T-cell function persist in vivo for 30-40 days and eventually differentiate into 'terminally exhausted' T cells $(10,11)$. Studies show that 'pre-exhausted' T cells express PD-1, T-cell-specific transcription factor-1 as well as the chemokine receptor $\mathrm{C}-\mathrm{X}-\mathrm{C}$ chemokine receptor type $5(12,13)$. PD-1 blockers primarily act on 'pre-exhausted' rather than 'terminally exhausted' T cells (10). Patients with melanoma with more 'pre-exhausted' $\mathrm{T}$ cells respond better to immune checkpoint blockade therapy for longer periods of time (10), indicating that increasing the numbers of 'pre-exhausted' $\mathrm{T}$ cells may contribute to better response to immune checkpoint blockers (10). Therefore, various approaches have been employed in an attempt to convert 'terminally exhausted' T cells into 'pre-exhausted' $\mathrm{T}$ cells or younger memory $\mathrm{T}$ cells $(9,14)$.

Tregs, a CD4 ${ }^{+} \mathrm{T}$-cell subset, specifically express CD25 and Foxp3 $(15,16)$. Tregs bind to antigen-presenting cells (APCs) via expressing CTLA-4, reduce the secretion of co-stimulators CD80 and CD86, and suppress the co-stimulatory signals of
T cells. It has been widely reported that Tregs inhibit the activation and function of T cells via these functions or directly act on T cells (17). By secreting immunosuppressive molecules, such as IL-10, IL-35, TGF- $\beta$, indole-2,3-dioxygenase and adenosine, Tregs lead to exhaustion of T cells (18). Activating Tregs can upregulate the expression of multiple suppressive immune checkpoints, such as PD-1, CTLA-4, TIM-3 and TIGIT (19), and also upregulate the expression of multiple molecules, which induce T-cell dysfunction, and transport molecules, such as CD39, CD73 and CCR4 (20). Reducing Treg numbers can reverse tumor-induced dysfunction of T cells (20). In brief, these findings indicate that changes of the subgroup and proportion of T cells in the TIME may affect the outcome of tumor immunotherapy.

$B$ cells. Abundant B cells may be found in tumors and tumor-draining lymph nodes, and they are common immune cells of the TIME (21). B cells, serving as APCs or recruiting DCs, participate in antigen presentation and consequently adjust T-cell differentiation and activation (22). The extent of infiltration by B cells, particularly memory B cells and plasma cells, was shown to be associated with the progression and prognosis of gastric cancer (23). Antibody-induced circulating immune complexes can inhibit antitumor immune response, leading to poor prognosis in patients with pancreatic ductal adenocarcinoma and bone marrow tumors $(24,25)$. Lymphotoxin secreted by B cells can accelerate tumor angiogenesis via activating STAT3 signaling, which in turn promotes cell proliferation in prostate cancer, melanoma and lung cancer (26). B cells can also promote bladder cancer metastasis by increasing the expression of extracellular matrix and remodeling-related genes (27). B cells, by secreting TGF- $\beta$, promote the production of reactive oxygen species and nitric oxide in myeloid cells, as well as the transformation of $\mathrm{CD} 4^{+} \mathrm{T}$ cells into Tregs, thereby suppressing the function of $\mathrm{CD}^{+} \mathrm{T}, \mathrm{CD} 8^{+} \mathrm{T}$ and $\mathrm{NK}$ cells, and accelerating tumor growth and metastasis $(26,28)$. CD20 monoclonal antibody was found to restrain the function of $\mathrm{CD}^{+}$and $\mathrm{CD}^{+} \mathrm{T}$ cells in melanoma (26).

In addition, B cells can directly destroy tumor cells and participate in antitumor immunity; they also express TNF-related apoptosis-inducing ligand to induce the lysis of melanoma cells and granulosin B to trigger the lysis of breast cancer cells, serving a protective role in patients with breast cancer and melanoma (26,29). Furthermore, activated B cells enhance T-cell-mediated antitumor responses in patients with cervical cancer (30). These findings suggest that B cells in the TIME have a dual function, as they may promote as well as inhibit tumor growth.

NK cells. NK cells, the predominant members of the innate lymphocyte family, are a class of natural immune cells that exhibit strong cytolytic activity against tumors (31). NK cells may be divided into the immature subset of CD56 ${ }^{+}$ CD16- cells that can secrete a large quantity of cytokines, and the mature subset of $\mathrm{CD}^{-} 6^{-} \mathrm{CD} 16^{+}$cells that are strongly cytotoxic $(32,33)$. NK cells recognize and destroy target cells via surface receptors, such as TIGIT, LAG-3 and PD-1. Allogeneic NK cells can discern and kill acute myeloid leukemia (AML) cells in hematopoietic stem cell 
transplantation (32), which is of significant therapeutic value in AML $(34,35)$. NK cell activity is modulated by blocking NK cell immune checkpoints, as NK cells express multiple immune checkpoint receptors, such as killer cell Ig-like receptor and CD94/NKG2A, and express multiple immune checkpoints, including TIM-3, TIGIT, CD96 and LAG-3, which can interact with their cognate ligands on tumor cells or on other immune cells. Moreover, NK cells are innate lymphoid cells that efficiently kill tumor cells without MHC specificity (36). A novel strategy often employed in tumor immunotherapy is through applying NK cell immune checkpoint inhibitors (37). The IgG4 anti-NKG2A antibody monalizumab was used to treat various solid tumors, and was shown to be generally well-tolerated $(37,38)$. The combination of monalizumab and the PD-1/PD-L1 disrupting agent durvalumab was used to treat colorectal cancer, which was also well-tolerated. The disease in 11 patients was stable and the disease control rate was $24 \%$ at 16 weeks in the expansion cohort. In addition, the anti-EGFR antibody cetuximab is an established therapeutic approach to squamous cell carcinoma of the head and neck, acting through induction of antibody-dependent cytotoxicity through the CD16 (Fc $\gamma$ RIII) receptor expressed on NK cells (39). The rationale for this approach relies on evidence that squamous cell carcinomas of the head and neck are strongly positive for HLA-E and are infiltrated by NK cells (40). This regimen was also well-tolerated, characterized mostly by grade 1-2 adverse events, with an overall response rate of $31 \%$ and disease stabilization rate of $54 \%$ (38). Furthermore, it is not necessary for NK cells to go through the process of antigen recognition, which indicates that NK cells can eliminate tumor cells without sensitization, preferentially eliminating tumor stem cells (41). It must be pointed out that the decrease in the number of NK cells may be associated with cancer risk (42). Compared with T cells, NK cells have a shorter persistence and may also represent a safer and more effective adoptive immunotherapy for solid tumors and hematological malignancies (43). Therefore, regulation of NK cell function and enhancement of NK cell toxicity are the dominant means of NK cell-based tumor immunotherapy $(44,45)$.

DCs. DCs mobilize naive $\mathrm{T}$ cells differentiate into effector cells and, thus, exert antitumor immunomodulatory effects by recognizing foreign antigens. Lysosomal-associated membrane glycoprotein 3-positive DCs, a mature subset of DCs, can express a variety of immune-related ligands and regulate the functions of a variety of lymphocytes and their subsets (46). Reducing the recruitment and the number of $\mathrm{CD} 03^{+} \mathrm{DC}$ leads to poor infiltration and dysfunction of $\mathrm{CD}^{+}$ $\mathrm{T}$ cells in the TIME (8). Compared with the untreated control, DC vaccines, alone or in combination with PD-1 inhibitors, have shown better tumor control and milder toxicity compared with the untreated control $(47,48)$. The aforementioned findings indicate that DCs can affect the function of other immune cells in TIME.

Mononuclear macrophages. Tumor-associated macrophages (TAMs), the most abundant population of tumor-infiltrating immune cells, refers to the macrophages located in or near the tumor (49). In response to tumor antigen stimulation, macrophages can differentiate into two subtypes: The M1 subtype, which promotes antitumor immunity, and the M2 subtype, which plays a role in tumor progression (49). TAMs, which tend to differentiate into the M2 subtype, are involved in tumorigenesis and tumor progression (50). It has been reported that an increase in TAMs is associated with poor prognosis in patients with cancer (51). Nanocomposites can promote the transformation of M2 to M1 macrophages, suppress tumor angiogenesis, reshape the TIME, present antigens to T cells, stimulate $\mathrm{T}$ cells to release cytokines, stimulate NK cells to infiltrate to tumor cells, and activate antitumor immune response to kill tumor cells $(52,53)$. Therefore, TAMs in the TIME may also affect the outcome of tumor immunotherapy.

\section{Non-immune cells and tumor immunotherapy}

Fibroblasts. Fibroblasts, an important type of mesenchymal cells, maintain organ structure and homeostasis by secreting cytokines, chemokines, growth factors and extracellular matrix. Carcinoma-associated fibroblasts (CAFs) are among the most important immune cells in TIME, which attract and mobilize immunocytes with inhibitory function through the release of cytokines, such as IL- 6 and TGF- $\beta$, as well as chemokines, such as $\mathrm{C}-\mathrm{X}-\mathrm{C}$ motif chemokine ligand (CXCL)1, CXCL12 and C-C motif chemokine ligand 2 (54). In addition, CAFs attract macrophages, $\mathrm{T}$ cells and NK cells to the tumor stroma (49) and they also induce resident macrophages and neutrophils to differentiate into M2 macrophages and N2 neutrophils, thereby serving an antitumor immunosuppressive role (55). It has been found that tumorigenic signals in melanoma interfere with T-cell-mediated antitumor responses by regulating the phenotype of CAFs (8). Paracrine signaling between tumor cells and fibroblasts can lead to chemoresistance, thereby negatively affecting chemotherapeutic efficacy in patients with breast cancer (56). CAFs induce phosphorylation of heat shock transcription factor-1 at $\mathrm{S} 326$, as well as proliferation, epithelial-to-mesenchymal transition and cancer stem cell-like transition of gallbladder cancer (GBC) cells by secreting thrombospondin-4 and binding to integrin $\alpha 2$, a transmembrane receptor on GBC cells (57). CAF exon LINC00659 accelerates the proliferation, invasion and migration of colorectal cancer cells via the microRNA-342-3p/annexin 2 axis (58). Activated CAFs promote the invasion and migration of ovarian cancer cells via the TGF- $\beta /$ collagen type VI alpha 1 chain signaling pathway (59). These findings indicate that CAFs in the TIME can affect the functions of other immune cells and cytokines, the efficacy of tumor immunotherapy and tumor growth.

Vascular endothelial cells. Vascular endothelial cells, another non-immune cell type in the TIME, highly express PD-L1, which suppress $\mathrm{CD}^{+} \mathrm{T}$-cell infiltration and facilitate Foxp3 ${ }^{+}$ T-cell aggregation, thus forming a type of 'immunosuppressive barrier' (60). There are reports that anlotinib can downregulate the expression of PD-L1 in vascular endothelial cells to suppress tumor growth (60). These findings indicate that the vascular endothelial cells in the TIME also affect the functions of other immune cells and immune checkpoints to affect tumor immunotherapy. 


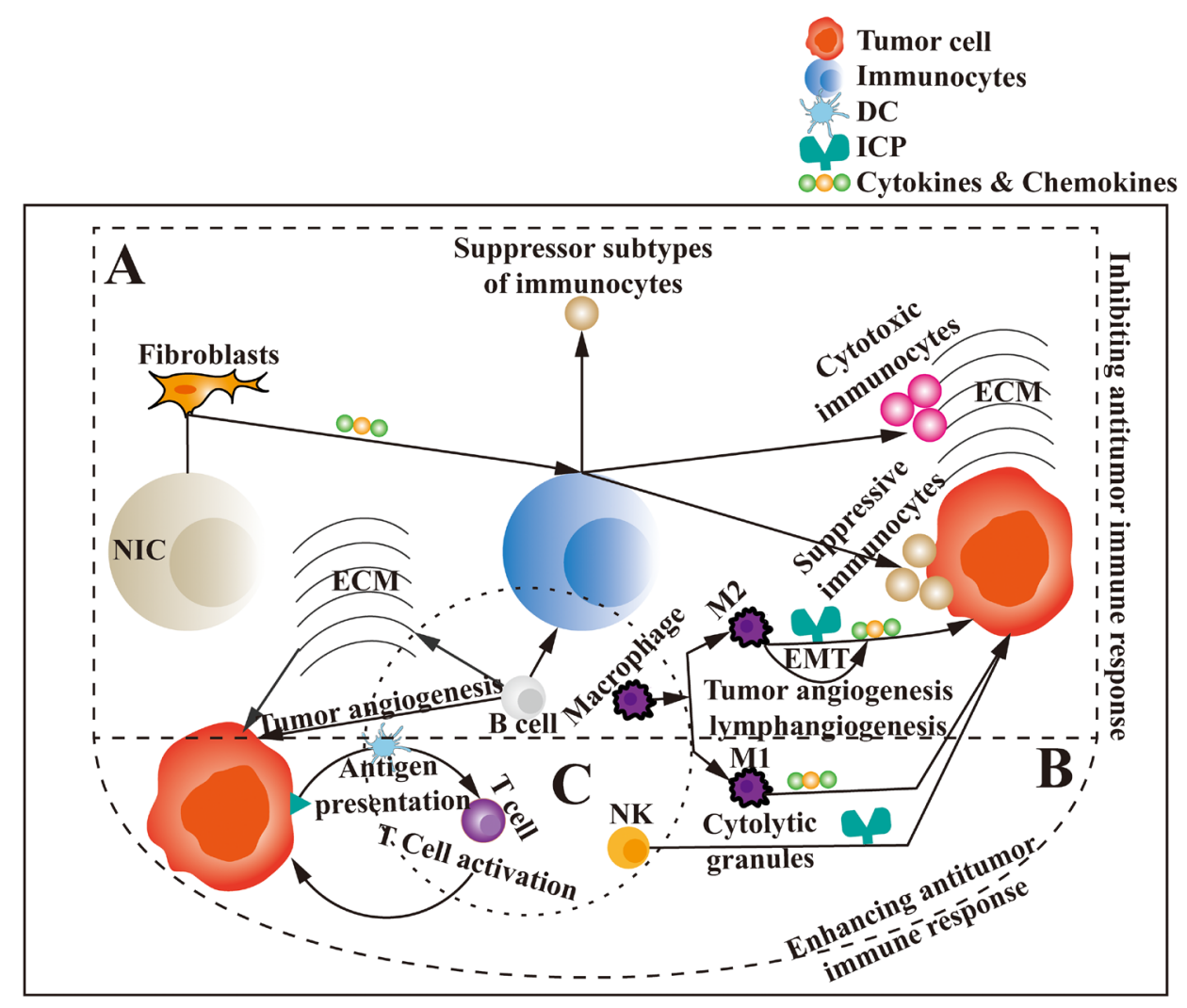

Figure 1. Associations and function of TIME components. TIME, an extremely complex microenvironment, which is mainly composed of tumor cells, immunocytes, NICs, stroma, cytokines, chemokines, ICPs and the interactions among them, plays a key role in the occurrence, development and metastasis of tumors. NICs, such as fibroblasts, induce the differentiation of immune cells to inhibitory subtypes by producing cytokines and chemokines, which attract the inhibitory immune cells to the tumor center and the cytotoxic immune cells, such as macrophages, $\mathrm{T}$ cells and NK cells, to the tumor matrix. B cells promote the growth and metastasis of tumors by inhibiting the function of immune cells, promoting the production of ECM and tumor angiogenesis. Macrophages promote tumorigenesis, progression and metastasis by differentiating into the M2 subtype to express ICPs, secrete cytokines and chemokines, and promote EMT, tumor angiogenesis and lymphangiogenesis. Therefore, the TIME can inhibit antitumor immune responses (part A). However, M1-type macrophages exert antitumor activity by secreting cytokines and chemokines. NK cells can induce tumor cell lysis by expressing immune checkpoints, releasing cytolytic granule perforin and granular enzyme. DCs present tumor antigens to T cells, which can induce T-cell activation to kill tumor cells. In conclusion, the TIME can enhance antitumor immune response (part B). Immune cells, composed of T cells, B cells, NK cells, macrophages and DCs (part C), can each be divided into several different or opposite subtypes that all play a role in inhibiting antitumor immune response or enhancing the different functions of antitumor immune response to inhibit or promote the occurrence, development and metastasis of tumors. TIME, tumor immune microenvironment; NICs, non-immune cells; ECM, extracellular matrix; ICP, immune checkpoint; NK, natural killer; DCs, dendritic cells; EMT, epithelial-to-mesenchymal transition.

\section{Cytokines and tumor immunotherapy}

IL-2, which activates and promotes the proliferation of T cells and NK cells, is the most promising cytokine in tumor immunotherapy (49). IL-2 activates aromatic hydrocarbon receptors to regulate $\mathrm{CD}^{+}{ }^{+}$T-cell failure (61). Second-generation IL-2 based on CD122 can induce the production of NARA1 interleukin. NARA1 with longer half-life in vivo can completely avoid binding to CD25 and stimulate proliferation and activation of $\mathrm{CD} 8^{+} \mathrm{T}$ cells and NK cells more effectively (62).

IL-12 induces immunosuppressive deficiency during $\mathrm{CD} 8^{+}$ T-cell differentiation (63). T cells pretreated with IL-12 can prevent $\mathrm{CD} 8^{+} \mathrm{T}$ cells from failing and enhance T-cell activation, thus boosting tumor clearance rate as well as reducing the risk of immune-related adverse events in patients with cancer (64). Recombinant IL-2, which has been approved by the US Food and Drug Administration for antitumor immunotherapy in metastatic kidney cancer and metastatic melanoma, has shown considerable therapeutic efficacy (49). It is reported that IL-12 does not only enhance the cytotoxicity of chimeric antigen receptor-T (CAR-T) cells, but can also reshape the
TIME with more prominent $\mathrm{CD} 4^{+} \mathrm{T}$-cell infiltration and fewer Tregs, which has a significant therapeutic effect on glioblastoma multiforme (65). It may be concluded that cytokines in the TIME can affect the function of immune cells and the efficacy of tumor immunotherapy.

\section{Immune checkpoints and tumor immunotherapy}

The application of immune checkpoint inhibitors has been a novel approach to and research hotspot in tumor immunotherapy in recent years, and has also shown considerable efficacy in the treatment of several tumors (66-68). First-generation immune checkpoint blockade tumor immunotherapy based on antibodies acts by blocking the interaction between receptors and/or ligand molecules, such as CTLA-4 and PD-1, that are involved in T-cell activation or reduced function (8).

PD-1 and PD-L1.PD-1, a member of the CD28 family, has two ligands with different expression patterns, PD-L1 (B7-H1) and PD-L2 (49), which can be used not only as an index of predicting tumor occurrence, but also as tumor prognostic index $(69,70)$. 
The combination of PD-1 with PD-L1, through the PI3K-AKT signaling pathway, releases immunosuppressive signals to inhibit the activation and proliferation of $\mathrm{T}$ cells, as well as to induce T-cell tolerance and exhaustion $(49,71)$. It can also directly affect the proliferation of cytotoxic T cells through the SH2 containing protein tyrosine phosphatase-2/Ras/MAPK signaling pathway (72). PD-L1 alone or in combination with LAG-3 blocker and CXCL13 can contribute to delayed tumor growth and is associated with survival benefits $(73,74)$. It has been pointed out that the monovalent bispecific antibody MEDI5752 can suppress PD-1 and CTLA-4, thus enhancing the blocking effect on activated PD- $1^{+} \mathrm{T}$ cells (75). Tumor immunotherapy with CTLA-4 and PD-1 monoclonal antibodies to block immune checkpoints has also achieved notable efficacy in a number of tumors $(6,20)$. Pembrolizumab and durvalumab, as PD-1 monoclonal antibodies, have also shown marked efficacy in patients with esophageal cancer and are available as second-line treatment in patients with esophageal squamous cell carcinoma (ESCC) (76), which has been approved for clinical use for ESCC in Japan (46).

$L A G-3$. LAG-3 is an immune checkpoint expressed on the surface of various lymphocytes, including activated $\mathrm{T}$ cells, Tregs, B cells, NK cells and plasmacytoid DCs (49). LAG-3, which has a similar structure to CD4 but higher affinity to APCs, can compete with MHC II complex antigens, thereby inhibiting T-cell activation (49). Anti-LAG-3 monoclonal antibody, as well as bispecific antibodies targeting LAG-3 and PD-L1, can block the immunosuppression mediated by LAG-3 and PD-L1, thus enhancing the activity of T cells, in order to suppress cell proliferation and tumor growth, which may prove beneficial for numerous patients with cancer $(77,78)$.

TIGIT. TIGIT is an immune checkpoint expressed on the surface of $\mathrm{CD}^{+}{ }^{+} \mathrm{T}$ cells, $\mathrm{CD} 8^{+} \mathrm{T}$ cells, NK cells and Tregs, which has become a new hotspot in tumor immunotherapy in recent years. TIGIT combined with CD155 expressed by APCs or tumor cells in turn inhibits T cells and NK cells $(79,80)$, which means that blocking TIGIT can facilitate the secretion of cytokines of $\mathrm{CD}^{+}$and $\mathrm{CD}^{+} \mathrm{T}$ cells, as well as restore the function of T cells and NK cells $(81,82)$. It has been reported that TIGIT-blocking antibodies can accelerate the expression of cytokines and chemokines, thereby enhancing the antitumor immune response (83). TIGIT monitoring in the peripheral blood of patients with cancer may be used as an early detection marker for anti-PD-1 immunotherapy (84). Given all the aforementioned factors, TIGIT is a potential immune checkpoint in the TIME that can affect the function of immune cells and the efficacy of tumor immunotherapy.

\section{Conclusions}

In conclusion, the TIME is complex and has numerous components that may serve as tumor immunotherapy targets; furthermore, these components can interact and affect one another, which greatly affects the efficiency of tumor immunotherapy (Fig. 1). Moreover, the TIME differs among different patients and at different time points. Therefore, fully elucidating the changes occurring in the TIME and its components during tumor development in specific patients may be the key to administering effective tumor immunotherapy. Further research must be conducted in follow-up studies on tumor immunotherapy, in order to improve the specificity and effectiveness of this treatment modality in cancer management.

\section{Acknowledgements}

Not applicable.

\section{Funding}

The present study was supported by grants from Natural Science Foundation of Guizhou Province (CN) (grant no. Qian ke he cheng guo [2019] 4444), Beijing Medical and health public welfare foundation (grant no. YWJKJJHKYJJ-B184054) and Key Project of the Science and Technology Ministry of China (grant no. 2017ZX10203206-005-002).

\section{Availability of data and materials}

Not applicable.

\section{Authors' contributions}

$\mathrm{CZ}$ contributed to literature review and search, as well as to the writing of the manuscript. QL and YX were involved in the design, acquisition and analysis of data and drafting the manuscript.. XG and WL contributed to the design of the study, interpretation of data and revised the manuscript critically for important intellectual content. All authors have read and approved the final manuscript.

\section{Ethics approval and consent to participate}

Not applicable.

\section{Patient consent for publication}

Not applicable.

\section{Competing interests}

The authors declare that they have no competing interests.

\section{References}

1. Hao M, Hou S, Li W, Li K, Xue L, Hu Q, Zhu L, Chen Y, Sun H, Ju $\mathrm{C}$ and Zhang C: Combination of metabolic intervention and T cell therapy enhances solid tumor immunotherapy. Sci Transl Med 12: eaaz6667, 2020.

2. Perets R, Bar J, Rasco DW, Ahn MJ, Yoh K, Kim DW, Nagrial A, Satouchi M, Lee DH, Spigel DR, et al: Safety and efficacy of quavonlimab, a novel anti-CTLA-4 antibody (MK-1308), in combination with pembrolizumab in first-line advanced non-small-cell lung cancer. Ann Oncol 32: 395-403, 2021.

3. Keung EZ, Lazar AJ, Torres KE, Wang WL, Cormier JN, Ashleigh Guadagnolo B, Bishop AJ, Lin H, Hunt KK, Bird J, et al: Phase II study of neoadjuvant checkpoint blockade in patients with surgically resectable undifferentiated pleomorphic sarcoma and dedifferentiated liposarcoma. BMC Cancer 18: 913, 2018.

4. Thorsson V, Gibbs DL, Brown SD, Wolf D, Bortone DS, Ou Yang TH, Porta-Pardo E, Gao GF, Plaisier CL, Eddy JA, et al: The immune landscape of cancer. Immunity 48: 812-830.e14, 2018. 
5. Eckstein M and Gupta S: New insights in predictive determinants of the tumor immune microenvironment for immune checkpoint inhibition: A never ending story? Ann Transl Med 7 (Suppl 3): S135, 2019

6. Beckermann KE, Dudzinski SO and Rathmell JC: Dysfunctional $\mathrm{T}$ cell metabolism in the tumor microenvironment. Cytokine Growth Factor Rev 35: 7-14, 2017.

7. Fukumura D, Kloepper J, Amoozgar Z, Duda DG and Jain RK: Enhancing cancer immunotherapy using antiangiogenics: Opportunities and challenges. Nat Rev Clin Oncol 15: 325-340, 2018.

8. Binnewies M, Roberts EW, Kersten K, Chan V, Fearon DF, Merad M, Coussens LM, Gabrilovich DI, Ostrand-Rosenberg S, Hedrick CC, et al: Understanding the tumor immune microenvironment (TIME) for effective therapy. Nat Med 24: 541-550, 2018.

9. Ando M, Ito M, Srirat T, Kondo T and Yoshimura A: Memory T cell, exhaustion, and tumor immunity. Immunol Med 43: 1-9, 2020

10. Miller BC, Sen DR, Al Abosy R, Bi K, Virkud YV, LaFleur MW, Yates KB, Lako A, Felt K, Naik GS, et al: Author correction: Subsets of exhausted $\mathrm{CD} 8^{+} \mathrm{T}$ cells differentially mediate tumor control and respond to checkpoint blockade. Nat Immunol 20: 1556, 2019.

11. Miller BC, Sen DR, Al Abosy R, Bi K, Virkud YV, LaFleur MW, Yates KB, Lako A, Felt K, Naik GS, et al: Subsets of exhausted $\mathrm{CD} 8^{+} \mathrm{T}$ cells differentially mediate tumor control and respond to checkpoint blockade. Nat Immunol 20: 326-336, 2019.

12. He R, Hou S, Liu C, Zhang A, Bai Q, Han M, Yang Y, Wei G Shen T, Yang X, et al: Follicular CXCR5- expressing CD8(+) T cells curtail chronic viral infection. Nature 537: 412-428, 2016.

13. Im SJ, Hashimoto M, Gerner MY, Lee J, Kissick HT, Burger MC, Shan Q, Hale JS, Lee J, Nasti TH, et al: Defining CD8 ${ }^{+}$T cells that provide the proliferative burst after PD-1 therapy. Nature 537: 417-421, 2016

14. Kagoya Y, Tanaka S, Guo T, Anczurowski M, Wang CH, Saso K, Butler MO, Minden MD and Hirano N: A novel chimeric antigen receptor containing a JAK-STAT signaling domain mediates superior antitumor effects. Nat Med 24: 352-359, 2018.

15. Cho MK, Park JG, Iwata $H$ and Kim EY: 2,3,7,8-Tetrachlorodibenzo-p-dioxin prompted differentiation to $\mathrm{CD} 44^{+} \mathrm{CD} 8 \mathrm{CD}^{-} 5^{+}$and $\mathrm{CD} 4^{+} \mathrm{CD} 8^{+} \mathrm{CD} 25^{+}$Tregs and altered expression of immune-related genes in the thymus of chicken embryos. Ecotoxicol Environ Saf 211: 111947, 2021.

16. Pompura SL, Wagner A, Kitz A, LaPerche J, Yosef N, Dominguez-Villar M and Hafler DA: Oleic acid restores suppressive defects in tissue-resident FOXP3 Tregs from patients with multiple sclerosis. J Clin Invest 131: e138519, 2021.

17. Shevyrev D and Tereshchenko V: Treg heterogeneity, function, and homeostasis. Front Immunol 10: 3100, 2020.

18. Wherry EJ and Kurachi M: Molecular and cellular insights into T cell exhaustion. Nat Rev Immunol 15: 486-499, 2015.

19. Kurtulus S, Sakuishi K, Ngiow SF, Joller N, Tan DJ, Teng MW, Smyth MJ, Kuchroo VK and Anderson AC: TIGIT predominantly regulates the immune response via regulatory $\mathrm{T}$ cells J Clin Invest 125: 4053-4062, 2015.

20. Zarour HM: Reversing T-cell dysfunction and exhaustion in cancer. Clin Cancer Res 22: 1856-1864, 2016.

21. Yuen GJ, Demissie E and Pillai S: B lymphocytes and cancer: A love-hate relationship. Trends Cancer 2: 747-757, 2016.

22. van de Veen W, Globinska A, Jansen K, Straumann A, Kubo T, Verschoor D, Wirz OF, Castro-Giner F, Tan G, Rückert B, et al: A novel proangiogenic B cell subset is increased in cancer and chronic inflammation. Sci Adv 6: eaaz3559, 2020.

23. Ni Z, Xing D, Zhang T, Ding N, Xiang D, Zhao Z, Qu J, Hu C, Shen X, Xue X and Zhou J: Tumor-infiltrating B cell is associated with the control of progression of gastric cancer. Immunol Res 69: 43-52, 2020

24. Satoh M, Takano S, Sogawa K, Noda K, Yoshitomi H, Ishibashi M, Mogushi K, Takizawa H, Otsuka M, Shimizu H, et al: Immune-complex level of cofilin-1 in sera is associated with cancer progression and poor prognosis in pancreatic cancer. Cancer Sci 108: 795-803, 2017.

25. Nakamura K and Smyth MJ: Myeloid immunosuppression and immune checkpoints in the tumor microenvironment. Cell Mol Immunol 17: 1-12, 2020.

26. Rubio AJ, Porter T and Zhong X: Duality of B Cell-CXCL13 axis in tumor immunology. Front Immunol 11: 521110, 2020.

27. Ou Z, Wang Y, Liu L, Li L, Yeh S, Qi L and Chang C: Tumor microenvironment B cells increase bladder cancer metastasis via modulation of the IL-8/androgen receptor (AR)/MMPs signals. Oncotarget 6: 26065-26078, 2015.
28. Bodogai M, Moritoh K, Lee-Chang C, Hollander CM, Sherman-Baust CA, Wersto RP, Araki Y, Miyoshi I, Yang L, Trinchieri G and Biragyn A: Immunosuppressive and prometastatic functions of myeloid-derived suppressive cells rely upon education from tumor-associated B cells. Cancer Res 75: 3456-3465, 2015.

29. Tabuchi Y, Shimoda M, Kagara N, Naoi Y, Tanei T, Shimomura A Shimazu K, Kim SJ and Noguchi S: Protective effect of naturally occurring anti-HER2 autoantibodies on breast cancer. Breast Cancer Res Treat 157: 55-63, 2016.

30. Rossetti RAM, Lorenzi NPC, Yokochi K, Rosa MBSF, Benevides L, Margarido PFR, Baracat EC, Carvalho JP, Villa LL and Lepique AP: B lymphocytes can be activated to act as antigen presenting cells to promote anti-tumor responses. PLoS One 13: e0199034, 2018.

31. Bald T, Krummel MF, Smyth MJ and Barry KC: The NK cell-cancer cycle: Advances and new challenges in NK cell-based immunotherapies. Nat Immunol 21: 835-847, 2020.

32. Tarazona R, Lopez-Sejas N, Guerrero B, Hassouneh F, Valhondo I, Pera A, Sanchez-Correa B, Pastor N, Duran E, Alonso $\mathrm{C}$ and Solana R: Current progress in NK cell biology and NK cell-based cancer immunotherapy. Cancer Immunol Immunother 69: 879-899, 2020.

33. Del Zotto G, Marcenaro E, Vacca P, Sivori S, Pende D, Della Chiesa M, Moretta F, Ingegnere T, Mingari MC, Moretta A and Moretta L: Markers and function of human NK cells in normal and pathological conditions. Cytometry B Clin Cytom 92: 100-114, 2017.

34. Handgretinger R, Lang P and André MC: Exploitation of natural killer cells for the treatment of acute leukemia. Blood 127: 3341-3349, 2016.

35. Myers JA and Miller JS: Exploring the NK cell platform for cancer immunotherapy. Nat Rev Clin Oncol 18: 85-100, 2021.

36. Kim N and Kim HS: Targeting checkpoint receptors and molecules for therapeutic modulation of natural killer cells. Front Immunol 9: 2041, 2018

37. Minetto P, Guolo F, Pesce S, Greppi M, Obino V, Ferretti E, Sivori S, Genova C, Lemoli RM and Marcenaro E: Harnessing NK cells for cancer treatment. Front Immunol 10: 2836, 2019.

38. Tinker AV, Hirte HW, Provencher D, Butler M, Ritter H, Tu D, Azim HA Jr, Paralejas P, Grenier N, Hahn SA, et al: Dose-ranging and cohort-expansion study of monalizumab (IPH2201) in patients with advanced gynecologic malignancies: A Trial of the Canadian cancer trials group (CCTG): IND221. Clin Cancer Res 25: 6052-6060, 2019.

39. Metes D, Galatiuc C, Moldovan I, Morel PA, Chambers WH, DeLeo AB, Rabinowich H, Schall R, Whiteside TL, Sulica A, et al: Expression and function of Fc gamma RII on human natural killer cells. Nat Immun 13: 289-300, 1994

40. Braud VM, Allan DS, O'Callaghan CA, Söderström K, D'Andrea A, Ogg GS, Lazetic S, Young NT, Bell JI, Phillips JH, et al: HLA-E binds to natural killer cell receptors CD94/NKG2A, B and C. Nature 391: 795-799, 1998.

41. Grossenbacher SK, Canter RJ and Murphy WJ: Natural killer cell immunotherapy to target stem-like tumor cells. J Immunother Cancer 4: 19, 2016

42. Imai K, Matsuyama S, Miyake S, Suga K and Nakachi K: Natural cytotoxic activity of peripheral-blood lymphocytes and cancer incidence: An 11-year follow-up study of a general population. Lancet 356: 1795-1799, 2000.

43. Lupo KB and Matosevic S: Natural killer cells as allogeneic effectors in adoptive cancer immunotherapy. Cancers (Basel) 11: 769, 2019.

44. Al-Attar A, Presnell SR, Clasey JL, Long DE, Walton RG, Sexton M, Starr ME, Kern PA, Peterson CA and Lutz CT: human body composition and immunity: Visceral adipose tissue produces IL-15 and muscle strength inversely correlates with NK Cell function in elderly humans. Front Immunol 9: 440, 2018.

45. Wang LX, Tong X, Li C, Giddens JP and Li T: Glycoengineering of antibodies for modulating functions. Annu Rev Biochem 88: 433-459, 2019.

46. Baba Y, Nomoto D, Okadome K, Ishimoto T, Iwatsuki M, Miyamoto Y, Yoshida N and Baba H: Tumor immune microenvironment and immune checkpoint inhibitors in esophageal squamous cell carcinoma. Cancer Sci 111: 3132-3141, 2020

47. Ding Z, Li Q, Zhang R, Xie L, Shu Y, Gao S, Wang P, Su X, Qin Y, Wang Y, et al: Personalized neoantigen pulsed dendritic cell vaccine for advanced lung cancer. Signal Transduct Target Ther 6: 26, 2021.

48. Teng CF, Wang T, Shih FY, Shyu WC and Jeng LB: Therapeutic efficacy of dendritic cell vaccine combined with programmed death 1 inhibitor for hepatocellular carcinoma. J Gastroenterol Hepatol 36: 1988-1996, 2021. 
49. Jia Y, Liu L and Shan B: Future of immune checkpoint inhibitors: Focus on tumor immune microenvironment. Ann Transl Med 8: 1095,2020

50. Chen Y, Song Y, Du W, Gong L, Chang H and Zou Z: Tumor-associated macrophages: An accomplice in solid tumor progression. J Biomed Sci 26: 78, 2019.

51. Hwang I, Kim JW, Ylaya K, Chung EJ, Kitano H, Perry C, Hanaoka J, Fukuoka J, Chung JY and Hewitt SM: Tumor-associated macrophage, angiogenesis and lymphangiogenesis markers predict prognosis of non-small cell lung cancer patients. J Transl Med 18: 443, 2020.

52. Han S, Wang W, Wang S, Yang T, Zhang G, Wang D, Ju R, Lu Y, Wang $\mathrm{H}$ and Wang L: Tumor microenvironment remodeling and tumor therapy based on M2-like tumor associated macrophage-targeting nano-complexes. Theranostics 11: 2892-2916, 2021.

53. Shan H, Dou W, Zhang Y and Qi M: Targeted ferritin nanoparticle encapsulating $\mathrm{CpG}$ oligodeoxynucleotides induces tumor-associated macrophage M2 phenotype polarization into M1 phenotype and inhibits tumor growth. Nanoscale 12: 22268-22280, 2020.

54. Costa A, Kieffer Y, Scholer-Dahirel A, Pelon F, Bourachot B, Cardon M, Sirven P, Magagna I, Fuhrmann L, Bernard C, et al: Fibroblast heterogeneity and immunosuppressive environment in human breast cancer. Cancer Cell 33: 463-479.e10, 2018.

55. De Jaeghere EA, Denys HG and De Wever O: Fibroblasts fuel immune escape in the tumor microenvironment. Trends Cancer 5: 704-723, 2019.

56. Maia A, Gu Z, Koch A, Berdiel-Acer M, Will R, Schlesner M and Wiemann S: IFN $\beta 1$ secreted by breast cancer cells undergoing chemotherapy reprograms stromal fibroblasts to support tumour growth after treatment. Mol Oncol 15: 1308-1329, 2021.

57. Shi Y, Sun L, Zhang R, Hu Y, Wu Y, Dong X, Dong D, Chen C, Geng Z, Li E and Fan Y: Thrombospondin 4/integrin $\alpha 2 / \mathrm{HSF} 1$ axis promotes proliferation and cancer stem-like traits of gallbladder cancer by enhancing reciprocal crosstalk between cancer-associated fibroblasts and tumor cells. J Exp Clin Cancer Res 40: 14, 2021

58. Zhou L,Li J, Tang Y and Yang M: Exosomal LncRNA LINC00659 transferred from cancer-associated fibroblasts promotes colorectal cancer cell progression via miR-342-3p/ANXA2 axis. J Transl Med 19: 8, 2021.

59. Zhang Y, Liu Z, Yang X, Lu W, Chen Y, Lin Y, Wang J, Lin S and Yun JP: H3K27 acetylation activated-COL6A1 promotes osteosarcoma lung metastasis by repressing STAT1 and activating pulmonary cancer-associated fibroblasts. Theranostics 11: $1473-1492,2021$.

60. Liu S, Qin T, Liu Z, Wang J, Jia Y, Feng Y, Gao Y and Li K: Anlotinib alters tumor immune microenvironment by downregulating PD-L1 expression on vascular endothelial cells. Cell Death Dis 11: 309,2020

61. Liu Y, Zhou N, Zhou L, Wang J, Zhou Y, Zhang T, Fang Y, Deng J, Gao Y, Liang X, et al: IL-2 regulates tumor-reactive $\mathrm{CD} 8^{+} \mathrm{T}$ cell exhaustion by activating the aryl hydrocarbon receptor. Nat Immunol 22: 358-369, 2021.

62. Sahin D, Arenas-Ramirez N, Rath M, Karakus U, Hümbelin M, van Gogh M, Borsig L and Boyman O: An IL-2-grafted antibody immunotherapy with potent efficacy against metastatic cancer. Nat Commun 11: 6440, 2020.

63. Renavikar PS, Sinha S, Brate AA, Borcherding N, Crawford MP, Steward-Tharp SM and Karandikar NJ: IL-12-induced immune suppressive deficit during $\mathrm{CD} 8^{+} \mathrm{T}$-cell differentiation. Front Immunol 11: 568630, 2020.

64. Tucker CG, Mitchell JS, Martinov T, Burbach BJ, Beura LK, Wilson JC, Dwyer AJ, Singh LM, Mescher MF and Fife BT: Adoptive T Cell Therapy with IL-12-preconditioned low-avidity $\mathrm{T}$ cells prevents exhaustion and results in enhanced $\mathrm{T}$ cell activation, enhanced tumor clearance, and decreased risk for autoimmunity. J Immunol 205: 1449-1460, 2020.

65. Agliardi G, Liuzzi AR, Hotblack A, De Feo D, Núñez N, Stowe CL, Friebel E, Nannini F, Rindlisbacher L, Roberts TA, et al: Intratumoral IL-12 delivery empowers CAR-T cell immunotherapy in a pre-clinical model of glioblastoma. Nat Commun 12: 444, 2021.

66. Jiang X, Ren L, Tebon P, Wang C, Zhou X, Qu M, Zhu J, Ling H, Zhang S, Xue Y, et al: Cancer-on-a-chip for modeling immune checkpoint inhibitor and tumor interactions. Small 17: e2004282, 2021.

67. Duchemann B, Pluvy J, Crestani B, Zalcman G and Nunes H: Immune checkpoint blockade for patients with lung cancer and idiopathic pulmonary fibrosis. Eur J Cancer 145: 179-182, 2021.
68. Ceresoli GL and Pasello G: Immune checkpoint inhibitors in mesothelioma: A turning point. Lancet 397: 348-349, 2021.

69. Wakita A, Motoyama S, Nanjo H, Sato Y, Yoshino K, Sasaki T, Kawakita Y, Liu J, Imai K, Saito H and Minamiya Y: PD-L1 expression is a prognostic factor in patients with thoracic esophageal cancer treated without adjuvant chemotherapy. Anticancer Res 37: 1433-1441, 2017.

70. Yoshida H, Nomizo T, Ozasa H, Tsuji T, Funazo T, Yasuda Y, Ajimizu H, Yamazoe M, Kuninaga K, Ogimoto T, et al: PD-L1 polymorphisms predict survival outcomes in advanced non-small-cell lung cancer patients treated with PD-1 blockade. Eur J Cancer 144: 317-325, 2021.

71. Tan CL, Kuchroo JR, Sage PT, Liang D, Francisco LM, Buck J, Thaker YR, Zhang Q, McArdel SL, Juneja VR, et al: PD-1 restraint of regulatory $\mathrm{T}$ cell suppressive activity is critical for immune tolerance. J Exp Med 218: e20182232, 2021

72. Liotti F, Kumar N, Prevete N, Marotta M, Sorriento D, Ieranò C, Ronchi A, Marino FZ, Moretti S, Colella R, et al: PD-1 blockade delays tumor growth by inhibiting an intrinsic SHP2/Ras/MAPK signalling in thyroid cancer cells. J Exp Clin Cancer Res 40: 22, 2021.

73. Marcq E, Van Audenaerde JRM, De Waele J, Merlin C, Pauwels P, van Meerbeeck JP, Fisher SA and Smits ELJ: The search for an interesting partner to combine with PD-L1 Blockade in Mesothelioma: Focus on TIM-3 and LAG-3. Cancers (Basel) 13: 282, 2021.

74. Yang M, Lu J, Zhang G, Wang Y, He M, Xu Q, Xu C and Liu H: CXCL13 shapes immunoactive tumor microenvironment and enhances the efficacy of PD-1 checkpoint blockade in high-grade serous ovarian cancer. J Immunother Cancer 9: e001136, 2021.

75. Dovedi SJ, Elder MJ, Yang C, Sitnikova SI, Irving L, Hansen A, Hair J, Jones DC, Hasani S, Wang B, et al: Design and efficacy of a monovalent bispecific PD-1/CTLA-4 antibody that enhances CTLA-4 blockade on PD- $1^{+}$activated T cells. Cancer Discov 11: $1100-1117,2021$

76. Kojima T, Shah MA, Muro K, Francois E, Adenis A, Hsu CH, Doi T, Moriwaki T, Kim SB, Lee SH, et al: Randomized phase III KEYNOTE-181 study of pembrolizumab versus chemotherapy in advanced esophageal cancer. J Clin Oncol 38: 4138-4148, 2020.

77. Lecocq Q, Keyaerts M, Devoogdt N and Breckpot K: The next-generation immune checkpoint LAG-3 and its therapeutic potential in oncology: Third time's a charm. Int J Mol Sci 22: $75,2020$.

78. Atkinson V, Khattak A, Haydon A, Eastgate M, Roy A, Prithviraj P, Mueller C, Brignone C and Triebel F: Eftilagimod alpha, a soluble lymphocyte activation gene-3 (LAG-3) protein plus pembrolizumab in patients with metastatic melanoma. J Immunother Cancer 8: e001681, 2020.

79. Harjunpää H and Guillerey C: TIGIT as an emerging immune checkpoint. Clin Exp Immunol 200: 108-119, 2020.

80. Judge SJ, Darrow MA, Thorpe SW, Gingrich AA, O'Donnell EF, Bellini AR, Sturgill IR, Vick LV, Dunai C, Stoffel KM, et al: Analysis of tumor-infiltrating NK and T cells highlights IL-15 stimulation and TIGIT blockade as a combination immunotherapy strategy for soft tissue sarcomas. J Immunother Cancer 8: e001355, 2020

81. Han HS, Jeong S, Kim H, Kim HD, Kim AR, Kwon M, Park SH, Woo CG, Kim HK, Lee KH, et al: TOX-expressing terminally exhausted tumor-infiltrating $\mathrm{CD}^{+} \mathrm{T}$ cells are reinvigorated by co-blockade of PD-1 and TIGIT in bladder cancer. Cancer Lett 499: 137-147, 2021

82. Li W, Deng C, Yang H, Lu X, Li S, Liu X, Chen F, Chen L, Shu X, Zhang L, et al: Expansion of circulating peripheral TIGIT $^{+} \mathrm{CD} 226^{+} \mathrm{CD} 4 \mathrm{~T}$ cells with enhanced effector functions in dermatomyositis. Arthritis Res Ther 23: 15, 2021.

83. Han JH, Cai M, Grein J, Perera S, Wang H, Bigler M, Ueda R, Rosahl TW, Pinheiro E, LaFace D, et al: Effective Anti-tumor response by TIGIT blockade associated with Fc $\gamma \mathrm{R}$ Engagement and myeloid cell activation. Front Immunol 11: $573405,2020$.

84. Simon S, Voillet V, Vignard V, Wu Z, Dabrowski C, Jouand N, Beauvais T, Khammari A, Braudeau C, Josien R, et al: PD-1 and TIGIT coexpression identifies a circulating CD8 T cell subset predictive of response to anti-PD-1 therapy. J Immunother Cancer 8: e001631, 2020.

This work is licensed under a Creative Commons Attribution-NonCommercial-NoDerivatives 4.0 International (CC BY-NC-ND 4.0) License. 